\title{
Development and Implementation of Aliens (Immigrant) Control and Information Tracking System
}

\author{
Mgbeafulike Ike $\mathbf{J}^{\mathbf{1}}$, Ejiofor Christopher $\mathbf{I}^{\mathbf{2}}$ \\ ${ }^{1,2}$ Dept. of Computer Science Chukwuemeka Odumegwu Ojukwu, University, Anambra State, Nigeria
}

*Corresponding Author: Mgbeafulike Ike J, Dept. of Computer Science Chukwuemeka Odumegwu Ojukwu, University, Anambra State, Nigeria

\begin{abstract}
The control and tracking of unauthorized immigrants into the country poses a major challenge to immigration authorities around the world. The Aliens control department of the Nigeria Immigration Service is concerned with the task of registering, monitoring and controlling the admission of aliens/immigrants into and out of Nigeria. Presently this task is manually done by the department designate. The aim of this study is to design and implement a computerized Aliens Control and Information Tracking System. The Object Oriented Analysis and Design Methodology (OOADM) were used to analyze our findings as well as developing the metamodel and information system. The system was designed and implemented as an online web based application capable of being accessed via the internet through the World Wide Web. The use of this replacement to the manual system will help to facilitate the handling of immigrant data storage and processing, tracking of illegal immigrants and also notify the immigration officers on immigrants with expired papers. Immigrant records can be found easily and quickly with no limit to the size of the records that can be stored.
\end{abstract}

Keywords: alien, immigrant, system, immigration, control, tracking, information system, notification

\section{INTRODUCTION}

The control and tracking of unauthorized immigrants into the country poses a major challenge to immigration authorities around the world. The escalating number of migrants in different countries not only has a huge environmental impact, but also results in security and economic problems. Immigration is the movement of people into a country to which they are not native in order to settle there, especially as permanent residents or future citizens ${ }^{(1)}$. Immigration can be best described as the act of foreigners passing or coming into a country for the purpose of permanent residence. Immigrants are motivated to leave their native countries for a variety of reason including a lack of local access to resources, a desire for economic prosperity, political issues, family re-unification, natural disaster, Poverty or the wish to change one's surroundings voluntarily ${ }^{(2)}$. An alien (immigrant) is a foreign born resident who is not a citizen by parentage or naturalization and who is still a citizen of another country. In Nigeria context, the definition of an alien or immigrant as provided in the immigration control regulations is narrowed down to mean " a person not a common wealth or Nigeria citizen or persons accorded immunity by reasons of diplomatic status, who enters or seeks to enter Nigeria. There are various types of aliens and each type depends on the motives for entry and this includes illegal aliens, immigrants, migrant workers, international visitor, refugees etc. Unauthorized immigration is the migration into a state in violation of the immigration laws and sovereignty of that nation. Illegal immigration raises many political, economical and social issues and has become a source of major controversy in developed countries and the more successful developing countries. It is for this reason that Immigration Control Bodies have been setup by different countries across the globe to tackle the issue of illegal immigration. Immigration or Border controls are measures used by a country to monitor or regulate its borders. The control of the flow of many people, animals and goods across a border may be controlled by government Customs services. Security is enforced by various kinds of Border Guards and Coast Guards. Official designations, jurisdictions and subordinations of these agencies vary ${ }^{(3)}$. 


\subsection{Statement of Problems}

Aliens control in Nigeria has been encountering enormous difficulties because of many problems. These problems includes but not limited to;

i. Manual registration and documentation of aliens in the country.

ii. Illegal immigrants are not easily identified

iii. Lack of appropriate measures for notifying or alerting the commission about alien resident expiration.

iv. Cumbersome method of tracking illegal aliens in the country.

This paper aims at design and implementation of an alien control and information tracking system for Nigeria Immigration services. This will assist in alien registration and in the identification of illegal immigrants. Generally, a control and information tracking system is used for observing of persons or objects on the move and supplying a timely ordered sequence of respective location data to a model. The purpose of a tracking system is to determine the location or direction of a target on a nearcontinuous basis. An ideal tracking system would maintain contact and constantly update the target's bearing range and elevation. The output of the tracking system can be sent to a control system, which stores the information and derives the target's motion and therefore its future position ${ }^{(4)}$.

\section{RELATED WORKS}

Immigration (derived from Latin: migratio) is the act of foreigners passing or coming into a country for the purpose of permanent residence. Immigration is made for many reasons, including economic, political, family re-unification, natural disaster, poverty or the wish to change one's surroundings voluntarily ${ }^{(5)}$. The United Nations found that, in 2005 alone, there were nearly 191 million international migrants worldwide, about 3 percent of the world population. This represented a rise of 26 million since 1990. Sixty percent of these immigrants were now in developed countries, an increase on 1990. Those in less developed countries stagnated, mainly because of a fall in refugees. Contrast that to the average rate of globalization (the proportion of cross-border trade in all trade), which exceeds 20 percent. The numbers of people living outside their country of birth is expected to rise in the future. Patrick ${ }^{(6)}$ gave a holistic view of human migration in his book "immigration law and practice in Nigeria. A complete guide book to immigration in Nigeria". According to him, human migration can be seen as movement from one place to another being an essential character of humanity. Movement of people into a country in violation of its prevalent immigration laws and statutes is termed as illegal immigration. With increasing income disparity between the developed and developing nations, illegal immigration has emerged as a major source of controversy in large parts of the developed world, raising political, social, and legal issues ${ }^{(7)}$. Some systems already exist in some developed countries that were designed for tracking illegal immigration. Some of the system includes (i) The J-BIS Biounit, an immigration control system that was introduced into Japanese airports. (ii) US-VISIT: United States Visitor and Immigrant Status Indicator Technology (commonly referred to as US-VISIT) is a United States Department of Homeland Security immigration and border management system. (iii) Oracle Immigration and Border Control: Oracle for Immigration and Border Control is the only comprehensive solution to create secure yet open borders for 21 st century global economies. These applications help in Managing and tracking of individuals within national boundaries; identifying change-of-circumstances for individuals overstaying visas and work permits

\section{Proposed SysteM AND IMPLEMENTATION}

The design and implementation of an alien control and information tracking system is the process of integrating computer based information system into the aliens unit of the immigration services. The alien system is made up of three modules - (i) The Administration module (ii) Alien Registration (iii) Tracking and Notification module. At the point of an aliens' arrival into the country, all data as regards his/her passport, travel details and employer/guarantor's data are captured and stored into the system. Based on the data stored, especially the duration of stay of the alien and also the geographical location of the alien, he or she is tracked. The system notifies the administrator from the status/alert environment, of the aliens' whose permit is close to expiration. These notifications are flagged as warning or illegal immigrant in the status page. Thus, this system will help to keep the aliens details more safe and secured, reduce the cumbersome work of sorting files stored in cabinets in order to 
locate immigrants that are due to leave the country, curb the rate at which illegal immigrants remain in the country without going to either renew their permit or returning back to the country they came from or otherwise as well as the control the activities of these immigrants as it relates to national values.

\subsection{Architecture of the System}

At a high level, the architecture of an application defines how different parts of the system are organized and logically separated yet ensuring that they work together. The architecture used for the system is three tiers: client tier, middle/web tier and the data tier as illustrated in Figure 4.1. Such an architecture is one of the most commonly used types of architecture for web-based applications as it provides greater application scalability, high flexibility, high efficiency, lower maintenance, and better reusability of components. The architecture of the new system is depicted below:

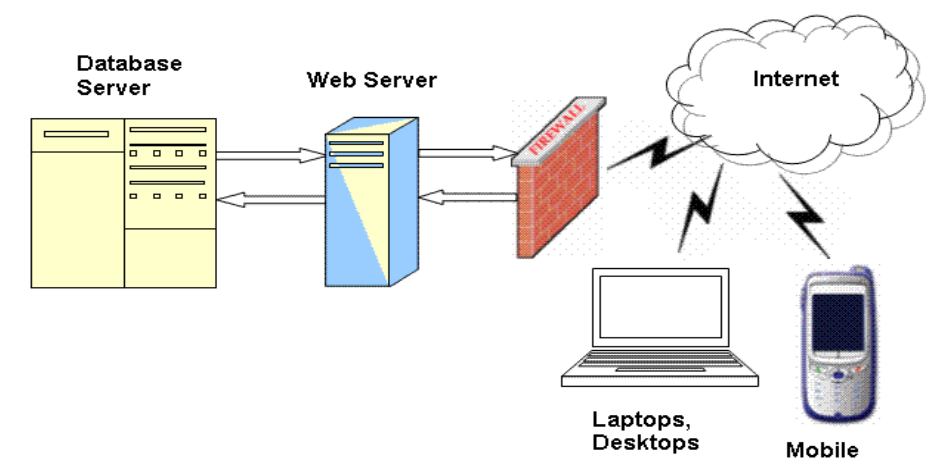

Figure3.1. Three-Tier System Architecture of the Proposed System

The client tier is the application's user interface containing data entry forms, report access links and client side application that are running on the web browser of the user machine. The aliens control section and other users of the system interact directly with the application through this user interface. It interacts with the web/application server to make requests and to retrieve data from the database. It then displays to the user the data retrieved from the server. The middle tier contains two parts of aliens control and information tracking application, i.e., the web server (application server) and the business logic. The web server (IIS) handles all HTTP requests coming from the client machines. The requests could be a request for adding new records, displaying existing records, or a request for report generation and others. It is also the web server which manages the responses that is forwarded to the client machines. The business logic component is responsible for handling all the core functionalities of the system such as input validation, performing calculations, report generation, access and retrieval of any data required by the client. When the data is submitted from the client machines, first it will be handled by the functions of the web server and then transferred to the business logic for processing. Again, the business logic processes the data and sends it either to the database or back to the web server, this is determined by the type of service required. It also interacts with an external system called Mobile telephone to accept notification information. The data tier layer is concerned with the data storage and persistence issues. It is implemented using SQL Server 2005 database. The database can either be stored on the web server itself or on a different machine; however it needs to be easily accessible by the web server.

\subsection{System Implementation}

Shown and described below are the various stages that were encountered during the implementation of the proposed system.

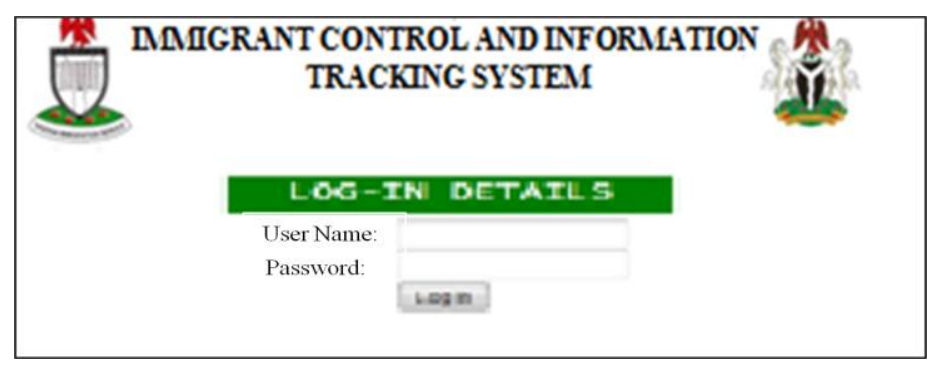

Figure3.2. Login Form 
This module provides the security layer through which only authenticated users will be allowed access to the system.

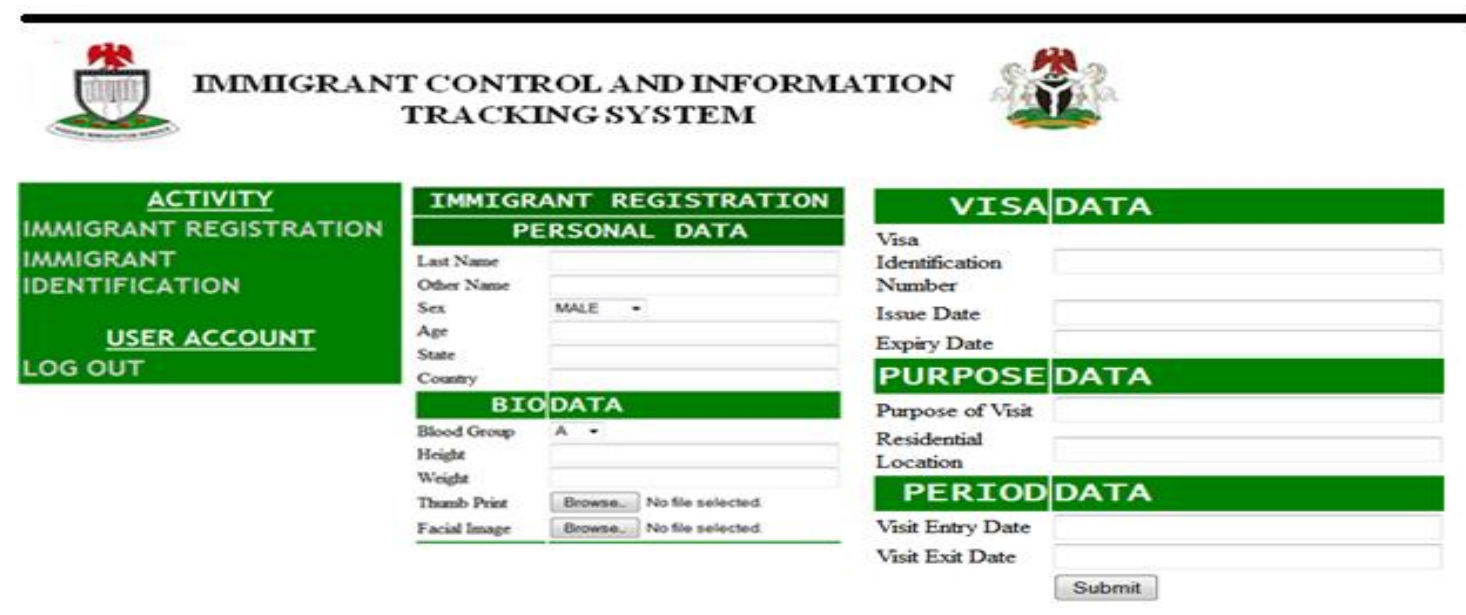

Figure3.3. Immigrant Registration Form

This screenshot is used for immigrant registration. . It contains necessary data about the immigrant. This gives the immigration administration the tool to register all aliens coming into the country and also able to identify and monitor them once they are in the country.

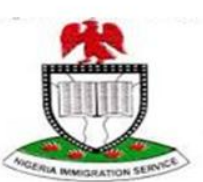

\section{IMMIGRANT CONTROL AND INFORMATION TRACKING SYSTEM}
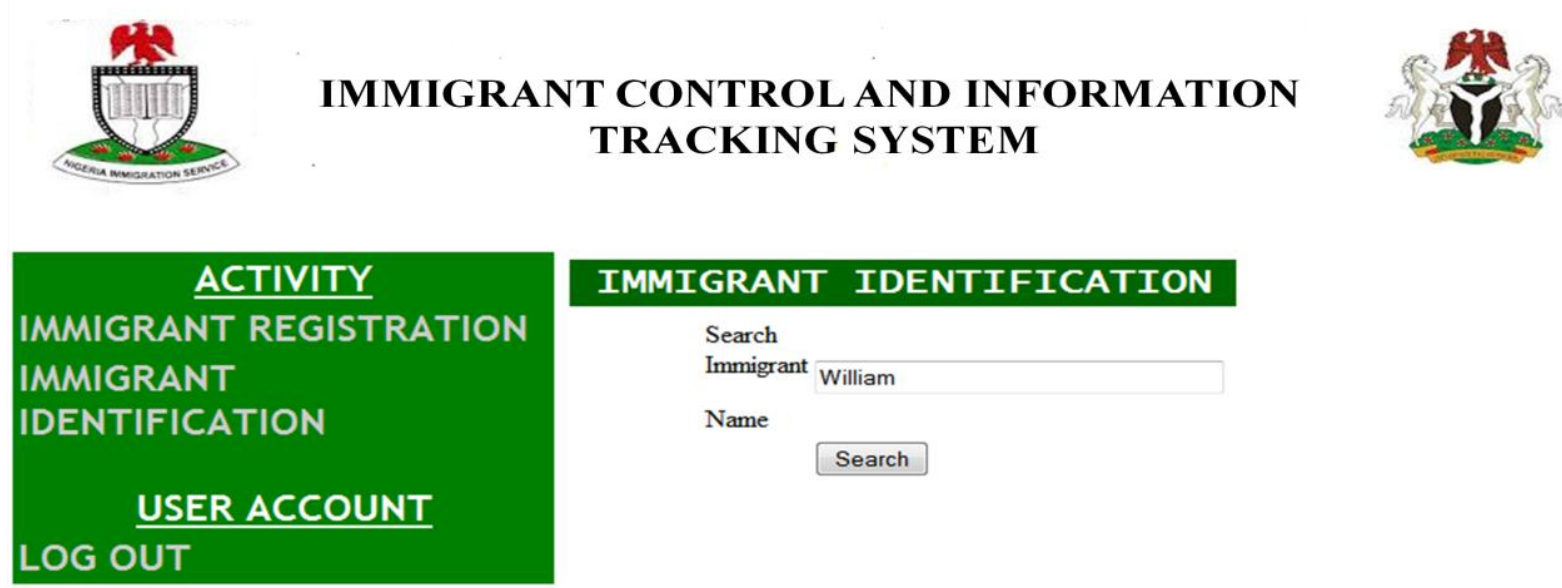

\section{IMMIGRANT IDENTIFICATION}

Search

Immigrant William

Name

Search

Figure3.4. Immigrant Identification Form

This form is used to search for information on the registered immigrants from the system's database

\subsection{Evaluation}

All modules of the Aliens Control and Information Tracking System were tested to ensure that they worked as was expected. All the input modules were tested for input data validation and data input collection. All modules were found to be accepting data and performing proper data validation. The output modules were tested to ensure that the data entered in the input module were displayed from the database correctly. All output modules displayed data as was expected.

\section{CONClusion}

This research project was aimed at the development of and Design of Aliens Control and Information Tracking System for Nigeria Immigration Service. The system will automate the whole process of immigration activities such as keeping track of immigrants coming into the country, the purpose of their visit, duration of their stay, their movement within the country and building a common interface to deliver fast and efficient application for mobile and onsite identification. The system was designed and implemented as an online web based application capable of being accessed via the internet through the World Wide Web. The use of this replacement to the manual system will help to facilitate the handling of immigrant data storage and processing, tracking of illegal immigrants and also notify the immigration officers on immigrants with expired papers. Immigrant records can be found easily and quickly with no limit to the size of the records that can be stored. 


\section{REFERENCES}

[1] Shahidul (2014)."Definition of \#immigration".tagdef.com. [online].Available from <https://tagdef. com/ immigration> (August 3, 2014).

[2] Masak, Sak(2015) "Immigration". NewYork Jets [online].Available from <http://jetsjersey2014. blogspot.com/2015/07/immigration.html> (Jul 4, 2015).

[3] X. D. Nabadda (2016) "WHAT IS HUMAN MIGRATION?". Linkedin. [online] <https://www.linkedin. com /pulse/whatishumanmigration-xarunta-dhaqanka-nabadda> (27, March 2016).

[4] "Garda National Surveillance Unit" Muncharoo [online] <http://www.muncharoo.com/main/index. php?s=Journal\%20of\%20Strength\%20\&\%20Conditioning\%20Research\&stype=topics\&sr=3350>(18 May 2017).

[5] Boustan, Adain May. "Fertility and Immigration." UCLA. 15 Jan. 2009.

[6] Patrick, U.A (2008). Immigration Law and Practice in Nigeria: A Complete Guide Book to Immigration in Nigeria.

[7] Facchini, G.; Steinhardt, M. F. (2011). "What drives U.S. Immigration policy? Evidence from congressional roll call votes". Journal of Public Economics. doi:10.1016/j.jpubeco.2011.02.008

[8] International Migration Report 2006PDF (89.4 KB). United Nations. Key Findings. Retrieved on 23 August 2017.

Citation: Mgbeafulike Ike J \& Ejiofor Christopher I (2017). Development and Implementation of Aliens (Immigrant) Control and Information Tracking System, International Journal of Research Studies in Computer Science and Engineering (IJRSCSE), 4(4), pp.31-35, DOI: http://dx.doi.org/10.20431/23494859.0404004

Copyright: (C) 2017 Mgbeafulike Ike J \& Ejiofor Christopher I. This is an open-access article distributed under the terms of the Creative Commons Attribution License, which permits unrestricted use, distribution, and reproduction in any medium, provided the original author and source are credited 